\title{
Avaliação da Atividade Antibacteriana do Óleo Essencial de Copaifera Multijuga Frente às Células Vegetativas de Alicyclobacillus acidoterrestris.
}

\author{
Angela Aparecida Silva (I), Idinea Fernandes Santos (I), Márcia \\ Maria Anjos (I), Jane Martha Graton Mikcha (I), Miguel Machinski \\ Júnior (I), Celso Vataru Nakamura (I), Benício Alves Abreu Filho (I) \\ (I) UEM - Universidade Estadual de Maringá (Avenida Colombo, 5790 - Jardim Universitário, \\ Maringá - PR, 87020-900)
}

\section{Resumo}

Os óleos essenciais podem ser empregados nas mais diversas áreas, inclusive na área alimentar, pois são classificados como GRAS (Generally Recognized as Safe) pela FDA (Food and Drug Administration). O Brasil é um grande exportador de suco de laranja concentrado, sendo este um produto de grande importância comercial e nutricional. Alicyclobacillus acidoterrestris é um bacilo acidotermorresitente e formador de esporos, fato que contribui para seu crescimento e desenvolvimento em alimentos acidificados, mesmo que estes passem por processo de pasteurização. A. acidoterrestris é utilizado como padrão no controle de qualidade do suco concentrado de laranja. Este trabalho tem como objetivo avaliar a ação do óleo essencial da Copaifera multijuga frente ao bacilo de A. acidoterrestris (CBMAI 0244T), com utilização da técnica da microdiluição seriada em microplaca de 96 poços. Com este ensaio foi possível avaliar a Concentração Inibitória Mínima (CIM) e a Concentração Bactericida Mínima (CBM). Em nossos ensaios foi utilizado o meio de cultura BAT (Bacillus acidoterrestris), com $\mathrm{pH} 4$ ajustado com $\mathrm{HCl} / \mathrm{NaOH} 1 \mathrm{~mol} / \mathrm{L}$. As concentrações avaliadas do óleo essencial variaram de 2.400 a $150 \mu \mathrm{g} / \mathrm{mL}$. Para o ensaio da CIM foram realizadas microdiluições seriadas contendo um volume total de $100 \mu \mathrm{L}$ da solução (meio de cultura e óleo essencial), com adição $5 \mu \mathrm{L}$ do inóculo padronizado em $104 \mathrm{UFC} / \mathrm{mL}$ em cada poço

\footnotetext{
Referência:

Angela Aparecida Silva, Idinea Fernandes Santos, Márcia Maria Anjos, Jane Martha Graton Mikcha, Miguel Machinski Júnior, Celso Vataru Nakamura, Benício Alves Abreu Filho. Avaliação da Atividade Antibacteriana do Óleo Essencial de Copaifera Multijuga Frente Às Células Vegetativas de Alicyclobacillus acidoterrestris. In: Anais do 12o Congresso Latinoamericano de Microbiologia e Higiene de Alimentos - MICROAL 2014 [= Blucher Food Science Proceedings, num.1, vol.1]. São Paulo: Editora Blucher, 2014. DOI 10.5151/foodsci-microal-276
} 
da microplaca e incubado por 24 horas a $45^{\circ} \mathrm{C}$. A CIM foi determinada como a menor concentração capaz de inibir o crescimento de A. acidoterrestris no poço da microplaca. Para avaliação da CBM, foram realizados microcultivos de $10 \mu \mathrm{L}$ em placa agar BAT dos poços que não houve crescimento bacteriano observado visivelmente. A CBM foi considerada como o não crescimento de colônias após plaqueamento seguido de incubação por 24 horas a $45^{\circ} \mathrm{C}$. A CIM e a CBM obtidas foram de 300 e $2.400 \mu \mathrm{g} / \mathrm{mL}$, respectivamente. Os resultados sugerem que o óleo essencial de Copaifera multijuga pode ser utilizado como agente antibacteriano frente a A. acidoterrestris, no entanto são necessárias mais pesquisas quanto ao mecanismo de ação, citotoxicidade e sua aplicação em sucos concentrados de laranja.

Palavras-Chave: Alicyclobacillus acidoterrestris, agente antibacteriano, Copaifera multijuga, suco de laranja

Agência de Fomento: PPG/UEM/CAPES. 